УДК 697.91.94.97

H. В. Жихарєва

Одеська національна академія харчових технологій, вул. Канатна, 112, Одеса, 65039, Україна

\title{
МЕТОД РОЗРАХУНКУ РІЧНОГО СПОЖИВАННЯ ХОЛОДУ СИСТЕМ КОНДИЦІЮВАННЯ ПОВІТРЯ
}

Використовуючи основні принциипи моделювання розроблено метод розрахунку річного споживання холоду систем кондиціювання повітря. Вихідними даними є: місце розташування будівлі та місцеві метеорологічні умови за даними багаторічних спостережень; розрахункове барометричний тиск; число робочих днів, змін; масові витрати припливного повітря $G$, зовнішнього $G_{н} i$ рециркуляційного $G_{p}$; коефіцієнт рециркуляиії; постійне або змінне значення ентальпї повітря $h_{p}$, що рециркулює, $i$ охолодженого повітря $h_{o x}$; температура $t_{6}\left({ }^{o} C\right)$ i ентальпія повітря $h_{6}$ в приміщенні. На основі бази даних табличних середньомісячних значень температур $t_{\text {н.м. }}\left({ }^{o} C\right)$ зовнішнього повітря і париіального тиску водяної пари $P_{н}(\kappa П а)$ методом інтерполяції сплайнів визначаєть-

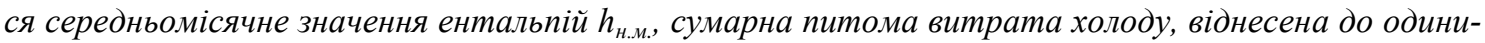
изі повітря виробництва систем кондиціювання повітря, річна витрата холоду з урахуванням безрозмірних множників. Розроблений метод дозволяє проводити зіставлення альтернативних варіантів систем кондиціювання повітря при їх оптимізації.

Ключові слова: Енергозбереження; Кондичіювання повітря; Витрата повітря; Моделювання; Повна теплота; Вологість; Витрата холоду; Оптимізація.

\section{Н. В. Жихарева}

Одесская национальная академия пищевых технологий, ул. Канатная, 112, Одесса, 65039, Украина

\section{МЕТОД РАСЧЕТА ГОДОВОГО РАСХОДА ХОЛОДА СИСТЕМ КОНДИЦИОНИРОВАНИЯ ВОЗДУХА}

Используя основные принципь моделирования разработан метод расчета годового потребления холода систем кондиционирования воздуха. Исходными данными являются: местоположение здания и местные метеорологические условия по данным многолетних наблюдений; расчетное барометрическое давление; число рабочих дней, смен; массовые расходы приточного воздуха $G$, наружного $G_{н}$, и рецииркуляционного $G_{p}$; коэффициент рециркуляиии; постоянное или переменное значение энтальпии рециркулируемого $h_{p}$ и охлажденного $h_{\text {ох }}$ воздуха; температура $t_{6}\left({ }^{o} C\right) u$ энтальпия воздуха $h_{6}$ в помещении. На основе базы данных табличных среднемесячных значений температур $t_{н . м}\left({ }^{\circ} \mathrm{C}\right)$ наружного воздуха и парцииального давления водяного пара $P_{н}(\kappa П а)$ методом

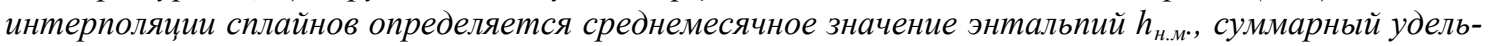
ный расход холода, отнесенный к единице воздухопроизводительности систем кондиционирования воздуха, годовой расход холода с учетом безразмерных множителей. Разработанный метод позволяет проводить сопоставление альтернативных вариантов систем кондиционирования в задаче оптимизации.

Ключевые слова: Энергосбережение; Кондиционирование воздуха; Расход воздуха; Моделирование; Полная теплота; Влажность; Расход холода; Оптимизация.

This work is licensed under the Creative Commons Attribution International License (CC BY).

http://creativecommons.org/licenses/by/4.0/

\section{I. ВСТУП}

Огляд методів енергозбереження в системах вентиляції та кондиціювання через масштабність проблеми ставить техніко-економічну задачу, рішення якої може бути корисним при проектуванні $[1,2,3,4]$.
У даній статті, використовуючи основні принципи моделювання, розроблено алгоритм розрахунку річного споживання холоду систем кондиціювання повітря.

Проектування систем кондиціювання повітря потребує системного аналізу та синтезу із застосуван- 
ням методів математичного моделювання. Для цього систему кондиціювання повітря підрозділяють на підсистеми й окремі елементи, для яких потім здійснюють кількісний аналіз на основі математичних моделей підсистем.

Декомпозиція як єдиної енергетичної системи представляється трьома основними енергетично взаємопов'язаними підсистемами $[2,3,5,6]$.

Основними рівняннями моделі є рівняння балансу повітря, повної теплоти $Q$, вологи $W$, газів $M$ і явної теплоти $Q_{я}$ в приміщенні [2, 3]:

$$
G_{n 1}+G_{Y 1}-G_{p}+\sum_{i=2}^{n} G_{n i}-\sum_{j=2}^{m} G_{y j}=0
$$

$$
\begin{aligned}
& G_{n 1} \cdot h_{n 1}-G_{y 1} h_{y 1}-G_{p} h_{p}+\sum_{i=2}^{n} G_{n i} h_{n i}-\sum_{j=2}^{m} G_{y j} h_{y j}+\Delta Q+\Delta Q^{\prime}=0 \\
& G_{n 1} d_{n 1}-G_{y 1} d_{y 1}-G_{p} d_{p}+\sum_{i=2}^{n} G_{n i} d_{n i}-\sum_{j=2}^{m} G_{y j} d_{y j}+\Delta W+\Delta W^{\prime}=0 \\
& G \frac{\chi_{\mathrm{n} 1}}{\rho_{\mathrm{n} 1}}-G_{y 1} \frac{\chi_{y 1}}{\rho_{y 1}}-G_{p} \frac{\chi_{p}}{\rho_{p}}+\sum_{i=2}^{n} G_{n i} \frac{\chi_{n i}}{\rho_{n i}}-\sum_{j=2}^{m} G_{y j} \frac{\chi_{y j}}{\rho_{y j}}+M_{\Gamma}=0
\end{aligned}
$$

$$
\begin{aligned}
& C p G_{n 1} t_{n 1}-C p G_{y 1} t_{y 1}-C p G_{p} t_{p}+ \\
& +C p \sum_{i=2}^{n} G_{n i} t_{n i}-C p \sum_{j=2}^{m} G_{y j} t_{y j}+\Delta Q я+\Delta Q^{\prime}=0,
\end{aligned}
$$

де $G_{п}, G_{\mathrm{y}}, G_{\mathrm{p}}-$ витрати припливного, видаляємого та рециркуляційного повітря, кг/с; $h_{n}, h_{\mathrm{y}} h_{\mathrm{p}}$ - ентальпія припливного, видаляємого та рециркуляційного повітря, кДж/кг; $d_{п}, d_{\mathrm{y}}, d_{\mathrm{p}}-$ вологовміст припливного, видалясмого та рециркуляційного повітря; $t_{\text {п }}, t_{\mathrm{y}}, t_{\mathrm{p}}$ температура припливного, видаляємого та рециркуляційного повітря; $x / p_{\text {п }} x / p_{\text {у }} x / p_{\mathrm{p}}$, концентрація та густина припливного, видаляємого та рециркуляційного повітря; $\Delta G_{\mathrm{M}}, \Delta Q_{\mathrm{M}}, \Delta W_{\mathrm{M}}, \Delta M_{\text {гм }}, \Delta Q_{\text {ям }}-$ дебаланси місцевої вентиляції по повітрю, повній теплоті, волозі, газам і явній теплоті.

На першому етапі оптимізується структура й продуктивність система кондиціювання повітря, характер і навантаження.

На другому етапі здійснюється оптимізація підсистем по різних технологічних i конструктивних параметрах.

Нарешті, на третьому етапі базові варіанти структури й продуктивності систем кондиціювання повітря оптимізується разом 3 оптимальними варіантами підсистем. При цьому розраховуються річні витрати холоду систем кондиціювання повітря $[1,2]$.

У цій статті розглянуто методика розрахунку річного споживання холоду систем кондиціювання повітря (СКП).

\section{II МЕТОД РОЗРАХУНКУ РІЧНОГО СПОЖИ- ВАННЯ ХОЛОДУ СИСТЕМ КОНДИЦЮЮАННЯ ПОВІТРЯ}

Розглянутий метод - це інструмент, який би дозволив фахівцям розрахувати річні витрати холоду СКП. Річні витрати теплоти, холоду та електроенергії для систем кондиціювання повітря розраховуються для робочої зміни або частини доби (далі зміни) 3 подальшим підсумовуванням при роботі систем в дві або більше число змін.

Визначаються середні параметри зовнішнього повітря за час роботи систем в теплий та холодний періоди року:

температура $t,{ }^{\circ} \mathrm{C}$ та ентальпія $h$, кДж/кг, зовнішнього повітря:

$$
\begin{gathered}
t_{\mathrm{T}}=t_{\mathrm{cp}, \mathrm{T}}+0,5 A_{\mathrm{T}} K_{l} K_{2} ; \\
t_{\mathrm{x}}=t_{\mathrm{cp}, \mathrm{x}}+0,5 A_{\mathrm{x}} K_{l} K_{2} ; \\
h_{\mathrm{T}}=h_{\mathrm{cp}, \mathrm{T}}+A_{\mathrm{e}, \mathrm{T}} K_{l} K_{2} ; \\
h_{\mathrm{x}}=h_{\mathrm{cp}, \mathrm{x}}+A_{\mathrm{e}, \mathrm{x}} K_{l} K_{2},
\end{gathered}
$$

де $t_{\mathrm{cp}, \mathrm{T}}, t_{\mathrm{cp}, \mathrm{x}}, h_{\mathrm{cp}, \mathrm{r}}, h_{\mathrm{cp}, \mathrm{x}}-$ середня температура повітря самого спекотного та холодного місяців;

$A_{\mathrm{T}}, A_{\mathrm{x}}, A_{\mathrm{e}, \mathrm{T}}, A_{\mathrm{e}, \mathrm{x}}-$ середня амплітуда температури, ${ }^{\circ} \mathrm{C}$ та амплітуда ентальпії, кДж/кг, самого спекотного і холодного місяців року, яка визначається;

$K_{I}$ - коефіцієнт, який визначається в залежності від тривалості роботи систем протягом доби;

$K_{2}-$ коефіцієнт, який визначається в залежності від часу, що доводиться на середину добового періоду роботи системи.

Середня за час роботи систем в році температура $\mathrm{i}$ ентальпія зовнішнього повітря визначаються за формулами:

$$
\begin{gathered}
t_{\Gamma}=t_{\mathrm{cp}, \Gamma}+0,25\left(A_{\mathrm{T}}+A_{\mathrm{x}}\right) K_{1} K_{2} ; \\
h_{\mathrm{\Gamma}}=h_{\mathrm{cp}, \Gamma}+0,5\left(A_{\mathrm{e}, \mathrm{T}}+A_{\mathrm{e}, \mathrm{x}}\right) K_{1} K_{2},
\end{gathered}
$$

де $t_{\mathrm{cp}, \Gamma}, h_{\mathrm{cp}, \Gamma}$ - середньорічна температура і ентальпія; $A_{\mathrm{T}}, A_{\mathrm{x}}, A_{\mathrm{e}, \mathrm{T}}, A_{\mathrm{e}, \mathrm{x}}-$ амплітуди температури і ентальпії, $K_{1}, K_{2}$ - коефіцієнти.

Річну витрату теплоти $Q$ (кДж/рік) на підігрів припливного повітря для прямоточної системи кондиціювання повітря, яка працює в одну зміну, можливо визначити за формулою:

$$
Q=0,143 n m C n G_{\text {п }} \Delta t M_{1} K_{3} K_{4},
$$

де $n$ - число робочих днів тижня;

$m$ - тривалість зміни, години; 
$C n$ - питома теплоємність повітря, кДж/кгК;

$G_{\text {п }}$ - максимальна витрата припливного повітря, кг/годину;

$\Delta t_{\mathrm{\kappa}}-$ різниця температур повітря до та після підігріву в самий холодний місяць року, яка визначається:

а) для прямоточної СКП

$$
\Delta t_{\mathrm{K}}=t_{\mathrm{\Pi}}-t_{\mathrm{x}}
$$

б) для СКП з визначенням рециркуляції

$$
\left.\Delta t_{\mathrm{K}}=t_{\text {пा }}-\left[t_{\mathrm{pu}}\left(1-G H / G_{\text {пा }}\right)+t_{\mathrm{x}} G H / G_{\text {пा }}\right]\right)
$$

де $t_{\mathrm{x}}$ - температура зовнішнього повітря в холодний період року, ${ }^{\circ} \mathrm{C}$;

$t_{\text {п }}$ - середня температура припливного повітря в саму холодну пору року;

$t_{\text {рц }}-$ температура рециркуляційного повітря в холодну пору року;

$G \mu, G_{\text {п }}$ - витрата зовнішнього та припливного повітря, кг/годину;

$M_{1}$ - тривалість періоду вжитку теплоти повітронагрівача:

$$
M_{1}=182,5\left(\Delta t_{\mathrm{K}} / \Delta t_{\mathrm{K}, \mathrm{\Gamma}}\right)^{0,5}
$$

Кількість годин праці повітронагрівача протягом року визначається за формулою:

$$
N_{1}=0,143 M_{1} n m K_{3} \text {, }
$$

де $M_{1}$ - тривалість періоду вжитку теплоти повітронагрівача, яка визначається за формулою (10);

$n$ - число робочих днів тижня;

$m$ - тривалість зміни, години;

$K_{3}$ - коефіцієнти, які залежать від тривалості періоду вжитку теплоти.

Річну витрату теплоти на перший підігрів повітря для прямоточної системи кондиціювання повітря і для системи з рециркуляцією можливо визначити так:

$$
Q=0,143 n m G_{\text {п }} \Delta h_{\mathrm{K}} M_{2} K_{3} K_{4},
$$

де $n$ - число робочих днів тижня;

$m$ - тривалість зміни, години;

$G_{\text {п }}$ - максимальна витрата припливного повітря, кг/годину;

$K_{3}$ та $K_{4}-$ коефіцієнти залежності від тривалості періоду вжитку теплоти;

$\Delta h_{\text {к }}$ - різниця температур повітря до та після підігріву в самий холодний місяць року, кДж/кг, яка визначається: для прямоточної СКП

$$
\Delta h_{\mathrm{K}}=h_{\mathrm{\kappa}, 3}-h_{\mathrm{x}} ;
$$

для СКП з використанням першої рециркуляції:

$$
\Delta h_{\mathrm{K}}=h_{\mathrm{\kappa}, 3}-\left[h_{\mathrm{pL}}\left(1-G_{H} G_{\mathrm{n}}\right)+h_{\mathrm{H}} G_{H} / G_{n}\right]
$$

де $h_{\kappa, 3}-$ ентальпія повітря на виході з камери зрошення в холодну пору року, кДж/кг; $h_{\mathrm{x}}$ - ентальпія повітря на вході в повітронагрівач в холодну пору року;

$h_{\text {рц }}$ - ентальпія рециркуляційного повітря в холодну пору року;

$$
M_{2}=182,5\left(\Delta h_{\mathrm{K}} / \Delta h_{\mathrm{\kappa}, \mathrm{\Gamma}}\right)^{0,5}
$$

де $\Delta h_{\kappa, \Gamma}-$ середньорічна різниця ентальпій.

Число часів роботи першого підігріву при роботі в одну зміну

$$
\mathrm{N}_{2}=0,143 \mathrm{~nm}_{2} \mathrm{~K}_{3}
$$

де $n$ - число робочих днів тижня;

$m$ - тривалість зміни, години.

Річна витрата теплоти на другий підігрів для прямоточної СКП та при використанні рециркуляції:

$$
Q_{2}=52 m n\left[\left(G_{\text {пा }}-G_{\mathrm{pц}, 2}\right) \Delta h_{\mathrm{r}}-3,6 Q_{\mathrm{r}, \mathrm{cp}}\right],
$$

де $G_{\text {п }}$ - витрата припливного повітря, кг/годину;

$G_{\mathrm{pц,2}}$ - витрата повітря приміщення, що поступає на другу рециркуляцію, кг/годину;

$Q_{\text {г,ср }}$ - середньорічні, середні за зміну тепловтрати (по повному теплу) обслуговуваного приміщення в Вт;

$\Delta h_{\Gamma}-$ середньорічна різниця ентальпій повітря приміщення і повітря на виході з камери зрошення або поверхневого повітроохолоджувача, кДж/кг:

$$
\Delta h_{\mathrm{r}}=0,5\left(h_{\mathrm{p}, \mathrm{T}}+h_{\mathrm{p} ц, \mathrm{x}}-h_{\mathrm{\kappa}, \mathrm{T}}-h_{\mathrm{\kappa}, \mathrm{x}}\right),
$$

де $h_{\mathrm{pц,},}, h_{\mathrm{pц,x}}-$ ентальпія рециркулюючого повітря приміщення, відповідно для теплого і холодного періодів, кДж/кг;

$h_{\mathrm{\kappa}, \mathrm{T}}, h_{\mathrm{\kappa}, \mathrm{x}}-$ ентальпія повітря на виході із зрошувальної камери або поверхневого повітроохолоджувача відповідно для теплого і холодного періоду, кДж/кг.

Середньорічні надлишки теплоти $Q_{\text {гсср }}$ Вт, слід визначати розрахунком при середньорічних значеннях параметрів зовнішнього клімату, а при їх відсутності допустимо приймати величину $Q_{\mathrm{r}, \mathrm{cp}}-$ середньої між надлишками теплоти в теплий i холодний періоди року. Якщо повітронагрівачі другого або зонального підігрівання системи кондиціювання повітря обслуговують декілька приміщень, то величина $Q_{\text {,ср }}$ - визначається як сума для всіх обслуговуваних приміщень.

Річна витрата холоду прямоточної СКП, кДж/г, визначається за формулою:

$$
Q=0,143 n m G_{\Pi} \Delta h_{\mathrm{T}} M_{3} K_{3} K_{4},
$$

де $n$ - число робочих днів тижня;

$m$ - тривалість зміни, години;

$G_{\text {п }}$ - максимальна витрата припливного повітря, кг/годину;

$h_{\mathrm{T}}$ - ентальпія повітря найспекотнішого місяця, визначається ;

$h_{3, \mathrm{~T}}$ - ентальпія повітря на виході з камери зрошення або повітроохолоджувача в теплий період року;

$M_{3}$ - тривалість періоду вжитку холоду за рік: 


$$
M_{3}=182,5\left(\Delta h_{\mathrm{T}} / \Delta h_{\mathrm{T}, \mathrm{\Gamma}}\right)^{0,5} .
$$

Число годин вжитку холоду за рік визначається за формулою

$$
N_{3}=0,143 \mathrm{~nm}_{3} K_{3},
$$

де $n$ - число робочих днів тижня;

$m$ - тривалість зміни, години;

$M_{3}$ - тривалість періоду вжитку холоду за рік по формулі

Річна витрата холоду для СКП з першою рециркуляцією, кДж/г, визначається за формулою

$$
Q_{\mathrm{p}, 1}=Q-\Delta Q_{\mathrm{p}, \mathrm{e}},
$$

де $Q$ - річна витрата прямоточної системи;

$\Delta Q_{\mathrm{p}, \mathrm{e}}$ - річна економія холоду, кДж/рік, визначається за формулою

$$
\Delta Q_{\mathrm{p}, \mathrm{e}}=0,143 n m\left(G_{\text {п }}-G_{\mathrm{p}}\right) \Delta h_{\mathrm{\tau}, \mathrm{p} \mu} M_{\mathrm{p}} K_{3} K_{4},
$$

де $n$ - число робочих днів тижня;

$m$ - тривалість зміни, години;

$G_{\text {п }}$ - максимальна витрата припливного повітря, кг/годину;

$M_{\text {рц }}$ - тривалість періоду роботи СКП з першою рециркуляцією при $\Delta h_{\mathrm{T}}=\Delta h_{\text {т,рц; }}$;

$G_{\text {рц }}-$ витрата повітря, що рециркулює, кг/год.

Річна витрата холоду для СКП з другою рециркуляцією, кДж/г:

$$
Q_{\mathrm{p}, 2}=\left(1-G_{2} / G_{\Pi}\right) Q,
$$

де $Q$ - річна витрата холоду;

$G_{2}$ - витрата повітря на другу рециркуляцію, кг/годину;

$G_{\text {п }}-$ витрата припливного повітря, кг/годину.

\section{III РЕЗУЛЬТАТИ РОЗРАХУНКУ СИСТЕМ КОНДИЦІЮВАННЯ ПОВІТРЯ}

Запропонований метод був апробований на основі розрахунку «DanX»- установки для вентиляції і кондиціювання повітря фірми Dantherm (Данія) 3 використанням матеріалів одного зі світових лідерів.
Установки DanX оснащені інтелектуальною системою управління, що дозволяє використовувати економічні i ефективні режими комфортного кондиціювання повітря, де нагрівається або охолоджується повітря 3 рекуперацією (або без рекуперації) припливного i витяжного потоків і з використанням рециркуляції внутрішнього повітря при підмішування зовнішнього повітря або без рециркуляції. Протягом цілорічної експлуатації той чи інший режим є найкращим для конкретного діапазону співвідношення ентальпій повітря в об'єкті зі штучним мікрокліматом і зовнішнього повітря [1,2,5,6].

Наприклад, в певному діапазоні температур і ентальпій зовнішнього повітря доцільно відключати тепловий насос, в тому числі найбільш енергоємний елемент - компресор, залишаючи тільки вентиляцію, або подавати зовнішнє повітря по байпасу повз рекуператора. Пропонований метод комплексно використовує ітераційні процедури і кубічні інтерполяції залежностей всіх теплофізичних властивостей повітря від температури, що змінюється на кожному витку ітерації.

Використано можливості обчислювальної середовища Mathcad, зокрема в окремих випадках для зменшення числа внутрішніх ітерацій використовувалися: підпрограми 3 відповідними циклами і службові обчислювальні блоки «Given-Minerr» або «GivenFind». Для основних величин, які ітеруються, в кінці кільця проводиться оцінка відносної похибки у відсотках.

Метод може бути використаний для різних теплових розрахунків і звичайно для 2-х основних режимів роботи зазначених установок: режим 1 - вентиляція через тепловий насос без рециркуляції витяжного повітря і без рекуперації повітряних потоків та режим 2 - рециркуляція внутрішнього повітря при підмішуванні свіжого повітря тільки за нормами для дихання людей, рекуперація припливного і витяжного потоків. Режим 2 враховує необхідність доведення ентальпії припливного потоку до значення ентальпії, що компенсує тепловтрати або теплоприпливи об'єктів, i, як правило, вимагає додаткової наявності в складі установки секції змішування потоків і секції калориферадовідника $з$ водяним або електричним нагріванням повітря (рисунок 1).

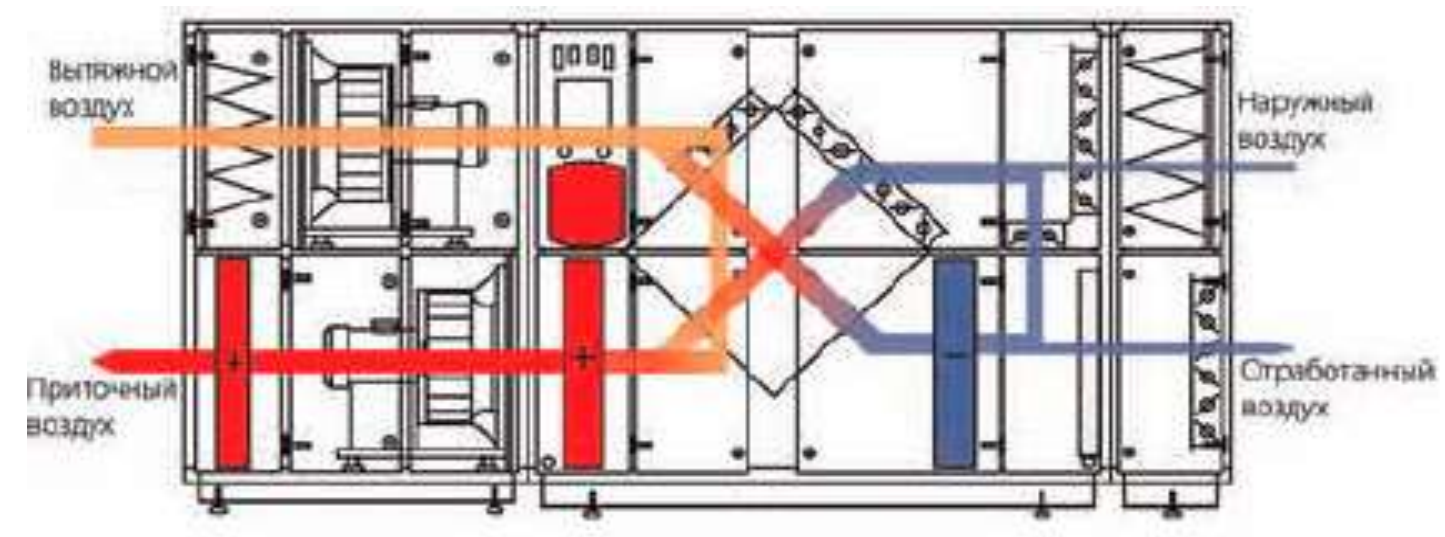

Рисунок 1 - Схема Dan-X для денного зимового режиму з підмішуванням свіжого повітря, 3 нагріванням, регенерацією і тепловим насосом. 
Нижче метод проілюстровано на прикладі найбільш складного для розрахунку режиму 2 роботи установки в зимовий період при низькій розрахунковій температурі $\left(-23{ }^{\circ} \mathrm{C}\right)$.

На торговий зал працюють дві установки. 3 приміщення кожною установкою викидається назовні 1999,9 м³ / год повітря і стільки ж по масі (за обсягом $1800 \mathrm{~m}^{3} /$ ч) подається свіжого повітря, а $19220 \mathrm{~m}^{3} /$ год внутрішнього повітря рециркулює. Фізичні параметри повітря визначалися автоматично кубічною сплайнінтерполяцією по таблицям 3 каталогу Dantherm, отриманих при атмосферному тиску 101.300 кПа. Характеристики обладнання визначалися за каталогом «Dantherm».

Річна витрата холоду при роботі 3 першою рециркуляцією $Q_{\mathrm{pц,1}}=98,2$ гДж/г, а для прямоточної СКП $\mathrm{Q}=102 г$ Дж/рік [3].

Маючи отримані вище дані по основним повітрооброблюючим секціям установки, складений тепловий баланс потоків повітря. Згідно 3 європейським стандартом EN 1886 рівень теплоізоляції класифікується в залежності від величини питомих тепловтрат через корпус $\left(U, B\right.$ T/ $\left(\mathrm{M}^{2}\right.$ K) на 5 класів: $\mathrm{T}_{1}, \mathrm{~T}_{2}, \mathrm{~T}_{3}, \mathrm{~T}_{4}, \mathrm{~T}_{5}$. За даними фірми [2] установки DanX мають величину $\mathrm{U}=1,2 \mathrm{BT} /(\mathrm{M} \cdot \mathrm{K}) \mathrm{i}$ відповідають класу теплоізоляції Т3 $(1<\mathrm{U}<1,4)$. Питомі втрати холоду теж класифікуються на 5 класів $\mathrm{TB}_{1}, \mathrm{~TB}_{2}, \mathrm{~TB}_{3}, \mathrm{~TB}_{4}, \mathrm{~TB}_{5}$. За даними фірми установки DanX мають величину $\mathrm{kB}$, відповідну класу $\mathrm{TB}_{3}(0,45$ $\left.<\mathrm{k}_{\mathrm{B}}<0,6\right)$. Метод розрахунку гарантує при коректних вихідних даних отримання практично корисного матеріалу для вибору необхідного типономінала установок розглянутого типу. Особливо метод ефективний для вибору систем кондиціювання повітря та його обладнання: секції рекуператора i калоріфера-доводчика та інш. [4,7].

\section{VI. ВИСНОВКИ}

Метод розрахунку річного споживання холоду гарантує при коректних вихідних даних отримання практично корисного матеріалу для вибору необхідного типономінала установок. Проводячи за даним методом розрахунки різних систем кондиціювання повітря можливо вибрати найефективнішу, особливо при необхідності порівняти обладнання різних фірм, наприклад Remak, Dantherm, Systemair та інші.

Розроблений метод дозволяє проводити зіставлення альтернативних варіантів систем кондиціювання повітря при їх оптимізації.

3 цього аналізу видно доцільність використання методу на третьому етапі оптимального проектування.

\section{ЛИТЕРАТУРА}

1. Перепека В. И. Расчеты систем кондиционирования и вентиляции. / В. И. Перепека, Н. В. Жихарева Одесса: «ТЭС», 2014. - 240 с.

2. Грачев Ю. Г. Основы оптимизации систем кондиционирования микроклимата.- Пермь: изд. Пермского политехнического института, $1987-79$ с + приложения.

3. Жихарєва Н. В. Моделювання та оптимізація систем кондиціювання повітря: Навчальний посібник / Н. В. Жихарева - Одеса: «ТЕС», , 2016. - 170 с + додатки

4. Жихарєва Н. В. Перепека В. І., Хмельнюк М. Г. Энергосбережение при эксплуатации приточных систем вентиляции и кондиционирования воздуха // Н. В. Жихарєва, В. И. Перепека, М. Г. Хмельнюк / Холодильна техніка та технологія, 2016. - Том. 52 №2. - С. 62-65.

5. Жихарсва Н. В. Осоливості розрахунку теплопипливів в приміщення при кондиціюванні повітря // Н. В. Жихарєва/ Холодильна техніка та технологія 2015. -Том. 51 №6. - С. 17-20.

6. Когут В. Е. Научно-технические основы создания эжекторных теплообменников и их применение в различных системах // В. Е. Когут / Холодильная техника и технология, 2016. -Том. 52 №2. - С. 25-28.

7. Kogut, V. E., Butovskyi, I. D., Zhikhareva N. V., Khmelniuk M. G. 2016. Anticipated costeffective effect from application of the ejector heat exchanger for condensation of light fraction hydrocarbon on the petroleum storage depot Refrigerationengineering and technology, No. 52 (3).- P. 25-28.

Отримана в редакції 17.05.2016, прийнята до друку 01.07.2016 
N. V. Zhikhareva

Odessa National Academy of Food Technologies, 112 Kanatnaia str., Odessa, 65039

\section{METHOD OF CALCULATION OF THE ANNUAL CONSUMPTION OF AIR CONDITIONING SYSTEMS COLD}

Using the basic principles of simulation the method for calculating of the annual consumption of cold by airconditioning systems was developed. The initial data are: location of the building and the local weather conditions according to the long-term supervision; estimated barometric pressure; the number of working days, shifts; mass flow rates of the supply air $G$, outdoor air $G_{H}$ and recirculation $G_{p}$; coefficient of recirculation; constant or variable value of the enthalpy of recycling air $h_{p}$ and cooled air $h_{\text {oh }}$; temperature $\left({ }^{\circ} \mathrm{C}\right)$ and the enthalpy of the indoor air.

On the basis of the database of the table monthly averages of temperatures $t_{n . m}\left({ }^{\circ} \mathrm{C}\right)$, outdoor air and water vapor partial pressure $P_{H}(\mathrm{kPa})$ the monthly average enthalpy $h_{n . m .}$ using the splines interpolation method, the total share of cold per unit of air conditioning systems air flow, the annual consumption of cold, taking into account the dimensionless factors are determined. The developed method allows to compare the alternative variants of air conditioning systems in the optimization problem.

Keywords: Energy Saving; Air Conditioning; Air Flow; Simulation; Full Heat; Humidity; Cold Flow; Optimization.

\section{REFERENCES}

1. Perepeka V. I., Zhikhareva N. V. (2014). The calculations of air conditioning and ventilation. Odessa "TEC", 240 p. (in Russian).

2. Grachev, Y. G. (1987). Basics of optimization of air conditioning systems mikroklimata. Perm Polytechnic Institute, 79 p., app. (in Russian).

3. Zhikhareva N. V. (2016). Modeling and optimization of air conditioning air: Uchebnoe posobye. Odessa: "TEC", 170 p., applications (in Russian).

4. Zhikhareva N. V, Perерека B. I., Khmelniuk M. G. (2016). Power saving at operation of the supply ventilation systems and air conditioning. Refrigeration engineering and technology, 52 (2), 62-65 (in Ukrainian). DOI: http://dx.doi.org/10.21691/ret.v52i2.63
5. Zhikhareva N. V. (2015).Calculation features of heat gain in an air conditioning room. Refrigeration engineering and technology, 51 (6), 17-20 (in Ukrainian). DOI: http://dx.doi.org/10.15673/0453-8307.6/2015.44778 6. Kogut V. E. (2016). Scientific-technological fundamentals of ejector heat exchangers development and their application in different systems. Refrigeration engineering and technology, 52(2), 25-28 (in Russian). DOI: http://dx.doi.org/10.21691/ret.v52i2.49.

7. Kogut, V. E., Butovskyi, I. D., Zhikhareva N. V., Khmelniuk M. G. (2016). Anticipated costeffective effect from application of the ejector heat exchanger for condensation of light fraction hydrocarbon on the petroleum storage depot Refrigeration engineering and technology, 52(3), 25-28.

DOI: http://dx.doi.org/10.15673/ret.v52i3.119 